\title{
Can Threat Increase Support for Liberalism? New Insights Into the Relationship Between Threat and Political Attitudes
}

Social Psychological and

Personality Science

$1-9$

(C) The Author(s) 2018

Article reuse guidelines:

sagepub.com/journals-permissions DOI: 10.1 I77/19485506/88I59|9 journals.sagepub.com/home/spp

@SAGE

\author{
Fade R. Eadeh' and Katharine K. Chang ${ }^{2,3}$
}

\begin{abstract}
The extant literature demonstrates that exposure to threat almost always increases support for political conservatism. But can threat increase the support for political liberalism? [AQ2]The current article provides evidence that threat can increase the aspects of political liberalism. Across three experiments, we find that experimentally manipulated threats to health-care access (Experiment I, $N=558$ ), pollution (Experiment 2, $N=184$ ), and corporate misconduct (Experiment $3, N=225)$ produced increased support for components of liberalism. These findings fill a notable gap in the literature, broadening larger theoretical discussions of threat as a psychological construct and current understandings of experimentally manipulated attitudinal change.
\end{abstract}

\section{Keywords}

threat, emotion, attitudes, political ideology

Threat: A person or thing likely to cause damage or danger.

Oxford English Dictionary (2018)

Threats come in all shapes and sizes. Some are acts of nature (e.g., tornados), some are caused by human error (e.g., fire caused by improper wiring), and others reflect malevolence (e.g., burglars breaking into your home). However, nearly all threats share one element: it motivates people to seek solutions to the problem at hand. In some cases, one can achieve this solution on one's own, but other threats require collective help. In the latter case, we often call on folks who are perceived as effective in dealing with that particular threat. When there is a fire in the basement, for example, one calls the fire department (see Lambert, Eadeh, \& Hanson, in press).

\section{"Issue Ownership" in Politics}

These considerations are relevant to the concept of issue ownership in political science (Egan, 2013; Petrocik, 1996). The idea is that different political groups are perceived as being effective at handling particular problems. In the United States, conservative parties (i.e., Republicans) are perceived as more effective at dealing with terrorism (Newport, 2014), whereas liberal parties (Democrats) are perceived as better handling health care and environmental issues (Saad, 2007). Across cultures, liberal parties have advantages dealing with the environment, social welfare policies, and health care. In contrast, conservatives have perceptual advantages in issues pertaining to law and order (Seeberg, 2017).

\section{An "Ideology-Affordance" Framework of Threat and Political Attitudes}

These considerations provide a foundation for a heuristically useful framework for understanding why certain threats enhance the attractiveness of conservativism or liberalism. Our framework is rooted in two assumptions. First, we assume political parties are (stereotypically) perceived as better handling certain problems. The second assumption is that priming a particular threat enhances the appeal of whichever political entity (or beliefs) best seen as "fixing" that threat. This latter assumption reflects an extension of the "affordance" concept (Gibson, 1977), which is defined as something that facilitates goal attainment. Affordances in our environment "are what it offers the animal, what it provides or furnishes" (Gibson, 1977 , p. 67 , emphases in original). Many things serve as affordances. Umbrellas afford staying dry; blankets afford warmth. It is not difficult to see how this construct explains how context can shape the evaluation of a given stimulus.

Political ideologies, too, represent affordances. Being faced with terrorist threat may enhance the aspects of conservatism.

\footnotetext{
' Goizueta Business School, Emory University, Atlanta, GA, USA

${ }^{2}$ National Institute of Mental Health, MD, USA

${ }^{3}$ Washington University, St. Louis, MO, USA
}

\section{Corresponding Author:}

Fade R. Eadeh, Goizueta Business School, Emory University, 1300 Clifton Boulevard, Atlanta, GA 30322, USA.

Email: fade.eadeh@emory.edu 
In particular, terrorist threat is likely to enhance the appeal of hawkish policies, which represents one aspect of conservatism within and outside of the United States. Our framework also provides for the possibility that threat could enhance the appeal of liberalism. For this to occur, the threat must correspond to issues for which liberals are seen as effective affordances.

\section{Relevance to Research on Threat and Political Attitudes}

At this point, it is useful to consider the kinds of threat researchers have studied. Because this literature is vast, we draw on a comprehensive review by Jost, Stern, Rule, and Sterling (2017), which analyzed 55 samples examining the impact of threat on political attitudes. Of these, a vast majority $(n=$ $45,82 \%$ ) focused on terrorism. The remaining samples mostly focused on xenophobic threats or the threat of physical harm from muggings or burglary. The extent of these and other findings allowed Jost and colleagues (2017) to conclude that "In light of these forces, it seems to be a remarkable fact of social and political psychology that subjective feelings and objective exposure to fearful and threatening stimuli contribute to observable 'conservative shifts' more often than not" (pp. 344-345).

Notably, these primes represent threats for which conservatives are perceived as more effective agents (Seeberg, 2017). According to our framework, these threats should enhance the appeal of conservative values. However, our model makes a more specific prediction: When these threats occur, they should most reliably pertain to aspects of conservatism that represent a solution to the threat. This is in fact the case (Eadeh, 2017[AQ3]; Lambert et al., 2010), as participants primed with terrorist threat find hawkish, "get tough" policies more appealing.

More important, our framework also explains the absence of studies showing threat can produce more favorable appraisals of liberalism. As noted above, many of the previous studies have focused on the kinds of threats for which conservatives are perceived as effective affordances. However, there is a wide diversity of threats in the universe. In short, we do not believe there is something "intrinsic" to threat predisposing people to enhance the value of conservatism. Rather, the critical issue is the type of threat examined. We are not aware of any research that studies threats for which liberals are seen as effective affordances. Our framework predicts priming these threats enhance the appeal of liberal—but not conservative-ideologies. The goal of our research was to fill this gap in the literature.

\section{Considerations of Affective Mediation}

The goal of the current article is to demonstrate threat-driven shifts to the left using three different types of threat. Of course, the activation of threat evokes a diversity of negative emotions including anger, fear, and anxiety (Huddy, Feldman, \& Cassese, 2007; Lambert et al., 2010; 2014). Although both anger and fear-related processes may be activated during such events, we predicted anger to be the causal mechanism for attitude change. This is because anger, unlike fear, is part of the approach system (Carver \& Harmon-Jones, 2009). More important for our purposes, anger, unlike fear, is the emotion that makes us take action and resolve the perceived threat (Cottrell \& Neuberg, 2005; Litvak, Lerner, Tiedens, \& Shonk, 2010).

In order to maximize the comparison of our results across studies, we performed three separate principal components analyses (PCAs) with varimax rotation on the entire mood inventory. Analyses across studies were virtually identical. A primary component emerged reflecting an "anger" dimension, containing extremely high loadings on several anger-related emotions (e.g., angry, mad) along with mood items corresponding to moral outrage (e.g., disgusted, revulsed). This finding is in line with literature suggesting that, in cases involving moral violations, anger and disgust reflect similar action tendencies (Hutcherson \& Gross, 2011; Nabi, 2002; see also GinerSorolla, Kupfer, \& Sabo, 2018[AQ4]). The variance accounted for this primary component was relatively high $(36.31 \%$ in Experiment 1, 26.50\% in Experiment 2, and 33.50\% in Experiment 3). Beyond anger, a component representing fear/anxiety also emerged (17.14\% in Experiment 1, $14.57 \%$ in Experiment 2, and $15.15 \%$ in Experiment 3).

In light of this convergence, a "generalized anger" composite was formed based on an average of 6 items that consistently loaded most highly across all three studies (i.e., $\mathrm{mad}$, angry, furious, disgusted, revulsed, sickened; $\alpha$ s $=.97, .97$, and .96 , respectively). In addition, we formed a fear/anxiety composite based on the average of 6 items that highly loaded on this component (nervous, scared, afraid, fearful, anxious, worried; $\alpha \mathrm{s}=.93$ across all three experiments). ${ }^{1}$

\section{Preliminary Study}

Before turning our attention to the main experiments, it was important to determine whether the primes presented here were equally threatening to other threats studied in the literature (e.g., terrorism). To this end, a separate group of participants took part in a preregistered study (https://osf.io/7waf5/). Participants were randomly assigned to one of the five priming conditions: the health-care prime (Experiment 1), the water pollution prime (Experiment 2), the corporate misconduct prime (Experiment 3), the threat of terrorism (see Online Supplement [Appendix A]), or a neutral control (Experiments 1-3). After condition assignment, participants completed two counterbalanced blocks of questions. The first block included a standard mood inventory, and a second block included a 14-item perceived threat questionnaire. For both dependent measures, we predicted participants in the experimental primes would report higher levels of negative affect and greater levels of perceived threat, compared to control. Moreover, we predicted that there would be no differences between the threat primes, in either affective experience or perceived threat. As seen in Figure $1 \mathrm{~A}$ and $1 \mathrm{~B}$, these are precisely what the data show. Indeed, there were no significant differences in perceived 


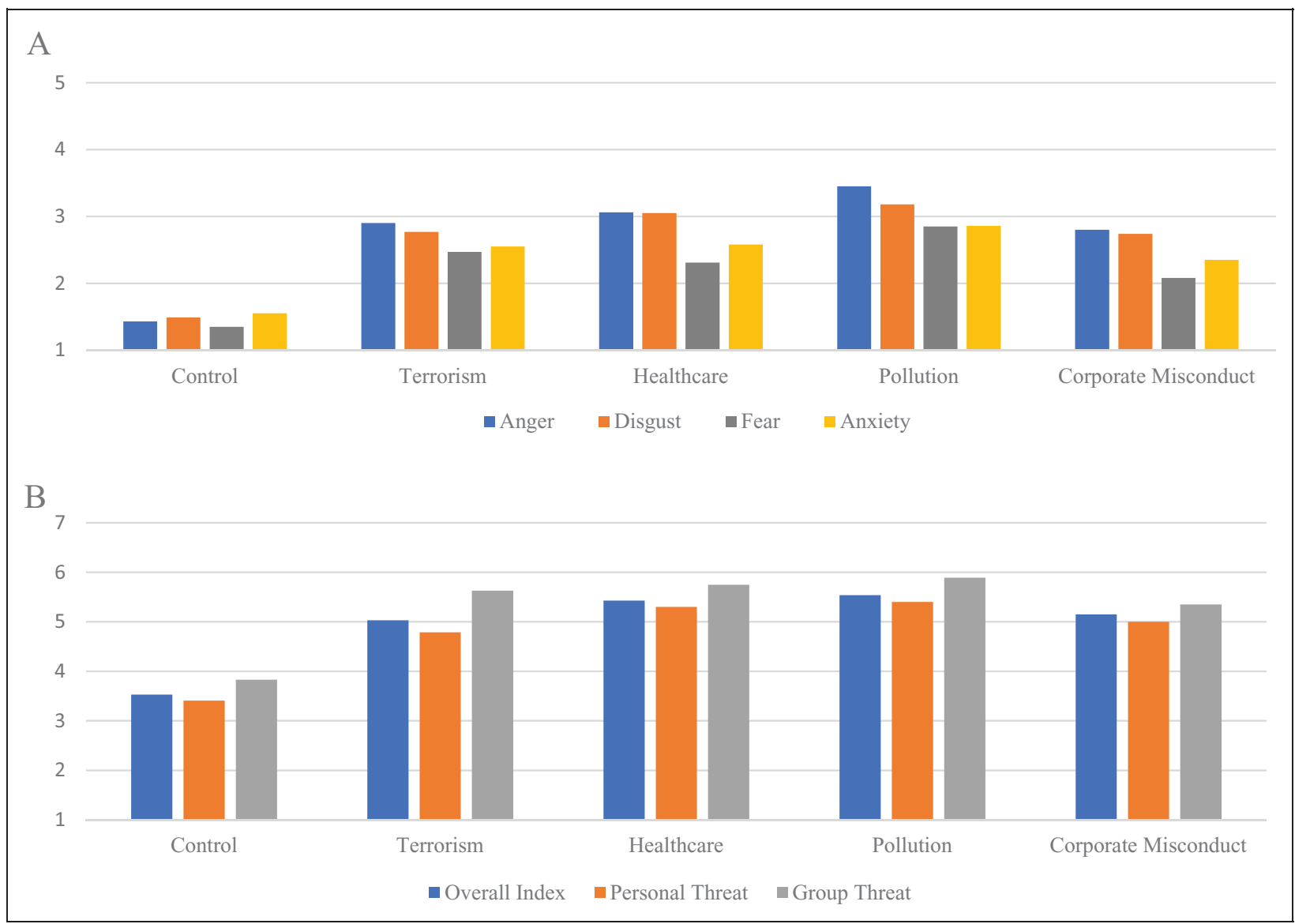

Figure I. Effects of priming condition on affective experience and perceived threat. (A) Effects of priming condition on affect. (B) Effects of priming condition on perceived threat indices.

threat, regardless of how it was operationalized (all $p \mathrm{~s}>.25$ ) nor were there differences in affective experience (all $p \mathrm{~s}>$ .09). [AQ5]The design, materials, and summary of the findings are available in Online Supplement (Appendix E).

\section{Experiment I}

Participants in this experiment read about a case where a young child was denied health insurance or a neutral control condition. Participants next completed a mood inventory, followed by an evaluation of political attitudes including attitudes toward health care. We also examined attitudes toward social conservatism, hawkish military attitudes, and general liberal attitudes.

\section{Method}

\section{Participants and Design}

Five hundred fifty-eight participants (171 male, 381 female, 2 other, 4 did not answer) were recruited from Amazon Mechanical Turk (MTurk). The design included a betweensubjects priming manipulation (health-care threat vs. control), followed by a standard mood inventory and a series of political statements.
In all experiments, (a) sample size was determined in advance, (b) aiming for at least $n=100$ per each experimental cell (before any data exclusions) to achieve suitable statistical power. Since no previous studies examined the link between threat and liberalism, we estimated a modest effect of Cohen's $f=.20$. This effect size indicated that 200 participants were needed to achieve power of 0.80 . Moreover, data from Experiment 1 represented all experimental manipulations of health-care threat (vs. control) in the first author's doctoral dissertation, with data collection taking place in fall 2016 and winter 2017, with no evidence the effects differed by wave. All participants were MTurk workers who completed between 100 and 500 HITs and had at least an $80 \%$ approval rating; each participant completed only one of our studies. ${ }^{2}$

We had three exclusion criteria for removing participants. First, we excluded noncitizens of the United States, as they may not possess knowledge about some political questions (e.g., Medicare). Noncitizens (about $2 \%$ in each sample) were paid but not included in the final sample. Second, participants completed an open-ended writing task, which provided an opportunity to screen participants who displayed disinterest by submitting nonsense characters or unrelated answers (e.g., $x \# \$ \& * M)$. In this case, three participants from Experiment 1, two from Experiment 2, and two from Experiment 3 were 
excluded from analyses. Finally, an attention check task was utilized (e.g., for the next question, please select "slightly disagree"). Participants failing this check (22 participants in Experiment 1, 14 participants in Experiment 2, and 9 participants in Experiment 3) were excluded from analyses.

\section{Health-Care Threat}

Participants read about the true story of Kyler Van Nocker, a 5 -year-old stricken with cancer who was denied health-care coverage by his parents' insurer. To assess spontaneous reactions to the article, participants were presented with the following prompt: "In the space provided, we would like you to list whatever thoughts and feelings you have about the article you just read. Five or six sentences are sufficient." Participants were free to write anything; the only constraint was answers needed to be between 200 and 5,000 characters. All newspaper articles are presented in the Online Supplement (Appendix A). ${ }^{3}$

\section{Control Prime}

Participants assigned to the control condition read an article about food allergies and then completed the same writing prompt.

\section{Assessment of Mood}

Immediately after the threat manipulation, participants completed a mood inventory in which they were presented with a randomized set of 35 mood adjectives (happy, proud, irritated, satisfied, mad, upset, sad, pleased, relaxed, unhappy, angry, irate, dejected, anxious, nervous, worried, confident, calm, content, relieved, dissatisfied, furious, scared, guilty, disgusted, revulsion, repulsed, afraid, fearful, interested, determined, excited, offended, nauseated, and sickened). For each adjective, participants evaluated their mood on a scale ranging from 1 (not at all) to 5 (very much so). We were most directly interested in the effects of anger (mad, angry, furious, disgusted, revulsed, sickened; $\alpha=.97$ ) but also created a fear/ anxiety index (nervous, scared, afraid, fearful, anxious, worried; $\alpha=.93$ ). In the analyses to follow, references to anger and "fear/anxiety" refer to composite indices.[AQ6]

\section{Political Attitudes Rating Task}

Following the mood inventory task, participants evaluated a series of 50 political statements, presented in a different randomized order for each participant (see Online Supplement [Appendix B] for a complete listing). All items were completed on a 7-point Likert-type scale, ranging from 1 (strongly disagree) to 7 (strongly agree). ${ }^{4}$

To test our main prediction, we formed a health-care attitudes index, based on 18 items. Some items were written in a proliberal direction (I would support regulation of privatized health insurance companies), whereas others were written in a pro-conservative direction (The government should have a minimal role in the health-care industry). After reverse coding the pro-conservative items, a composite of all 18 items displayed high levels of reliability $(\alpha=.91)$.

To examine whether our priming condition altered other political attitudes, we formed social liberalism, social conservatism, and hawkish military indices. Social liberalism was constructed from a battery of 9 items (e.g., I am happy that same-sex marriage is now legalized), whereas social conservatism was based off an 11-item composite (e.g., Abortion should be outlawed in all circumstances). Both composites displayed high levels of reliability ( $\alpha \mathrm{s}=.83$ and .88 , respectively). Finally, hawkish military attitudes were constructed from a battery of 12 items (The best way to ensure peace is through military strength) after reverse scoring as necessary $(\alpha=.94)$. Because we did not have strong predictions of betweensubjects differences on these indices, we present these findings in supplemental analyses.

\section{Results}

\section{Effects of Health-Care Threat on Mood}

We expected and found higher levels of anger in the threat versus control condition, $M=3.32$ (95\% confidence interval [CI] $=[3.22,3.43])$ versus $M=1.13(95 \%$ CI $[1.02,1.24]), F(1$, $556)=782.77, p<.001, \eta^{2}=0.59$, and (b) higher levels of fear/anxiety in the threat versus control condition, $M=2.23$ $(95 \%$ CI $[2.13,2.33])$ versus $M=1.30$ (95\% CI [1.20, $1.40]), F(1,556)=171.43, p<.001, \eta^{2}=0.24$.

\section{Effects of Health-Care Threat on Political Attitudes}

We expected and found being primed with the health-care threat (vs. control) increased support for liberal health-care attitudes, $M \mathrm{~s}=5.22(95 \% \mathrm{CI}[5.11,5.33])$ versus $5.02(95 \% \mathrm{CI}$ $[4.91,5.13]), F(1,556)=6.06, p=.01, \eta^{2}=0.01$.

\section{Mediation Analyses}

To test for mediation, we used Model 4 of Hayes's (2018) Process macro. Experimental condition served as the independent variable $(X)$, anger $\left(M_{1}\right)$ and fear/anxiety $(M 2)$ served as the mediators $(M)$, and health-care attitudes served as the outcome measure (Y). These findings, presented in Figure 2, show evidence for mediation, confirming that anger, but not fear/anxiety, contributed to increased support for liberal health-care attitudes.

\section{Supplemental Analyses}

Analyses revealed no effects for social liberalism, $M \mathrm{~s}=5.07$ versus $4.14, F(1,556)=1.53, p=.22, \eta^{2}=0.00$, nor did we observe between-subject differences on social conservatism, $M \mathrm{~s}=3.35$ versus $3.25, F(1,556)=0.82, p=.37$, or hawkish attitudes, $M \mathrm{~s}=3.84$ versus $3.88, F(1,556)=0.11$, $p=.74$. 


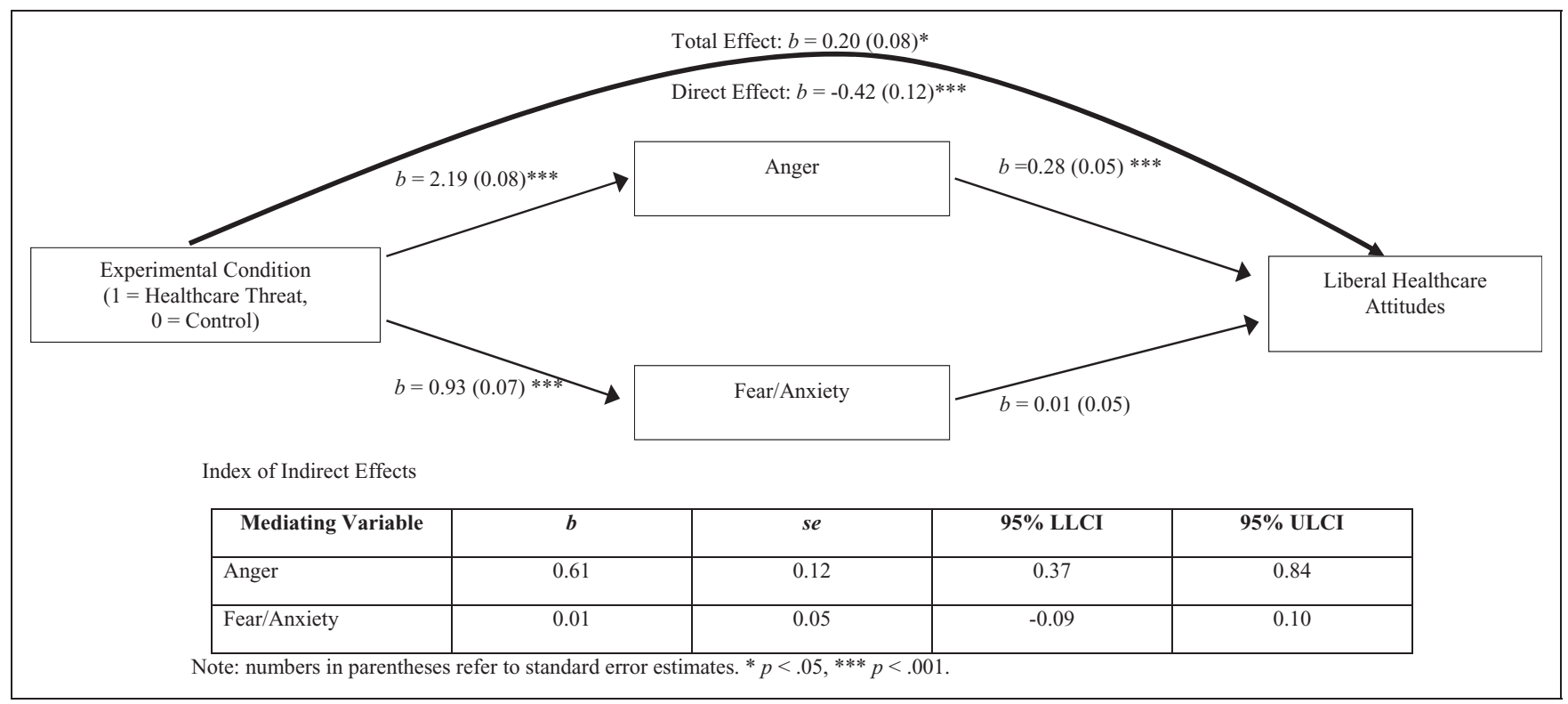

Figure 2. Mediation analyses on liberal health-care attitudes, Experiment I, anger $(N=558)$. Index of indirect effects.

\section{Experiment 2}

Experiment 2 represents the second test of our theoretical model, which predicts pollution threats (vs. control) will increase the support for related aspects of political liberalism. To offset the possibility, our findings were due to how threat was operationalized, participants read about either a water or air pollution threat. After condition assignment, participants rated their mood and a series of political attitudes.

\section{Method}

\section{Participants and Design}

One hundred eight-four (62 male, 120 female, 2 did not answer) U.S. participants were recruited from MTurk. The design included a between-subjects manipulation of priming type (air pollution threat vs. water pollution threat vs. control). After completing a standard mood inventory, all participants evaluated a series of political statements, presented in counterbalanced order for each participant. Because we anticipated a similar pattern across the two pollution threats, half of the participants were assigned to the control condition, with the remaining participants split evenly across the threat primes. As expected, there were no differences in affect nor were there differences in political attitudes across the two priming manipulations. For these reasons, we merged the two priming conditions together.

\section{Air Pollution Prime}

Participants in this condition read about Kavon Cooper, a 12 -year-old child who died from Asthma in Evansville, IN. The article detailed Kavon's bout with asthma and the proximity of extreme pollution near his home. After reading this article, participants completed the same writing task from Experiment 1. Participants were free to write anything they wished; the only constraint was that answers needed to be between 200 and 5,000 characters.

\section{Water Pollution Prime}

Participants in this condition read about the story of Josephine Reed, a 2-year-old who suffered heavy metal poisoning as a result of drinking polluted water. After reading this article, participants completed the same writing task from Experiment 1. Participants were free to write anything they wished; the only constraint was that answers needed to be between 200 and 5,000 characters.

\section{Control Prime}

The control prime was identical to Experiment 1. Participants were able to write anything they wished about the article, with similar length constraints to the pollution prime conditions.

\section{Mood and Political Attitudes}

The method and materials in this study were similar to our earlier study. Our anger and fear/anxiety mood composites were identical ( $\alpha \mathrm{s}=.97$ and .93 , respectively). Because the threat in this study was related to the environment, we generated a set of 16 items to assess participants' views on environmental matters in the United States. Sample items on this scale included support for clean energy solutions, funding the Environmental Protective Agency, and the role of government in regulating private industries. After reverse scoring as necessary, a composite of all 16 items indicated high levels of reliability $(\alpha=.92)$. We hypothesized that pollution threats would alter environmental attitudes in a pro-liberal direction. Finally, we measured 


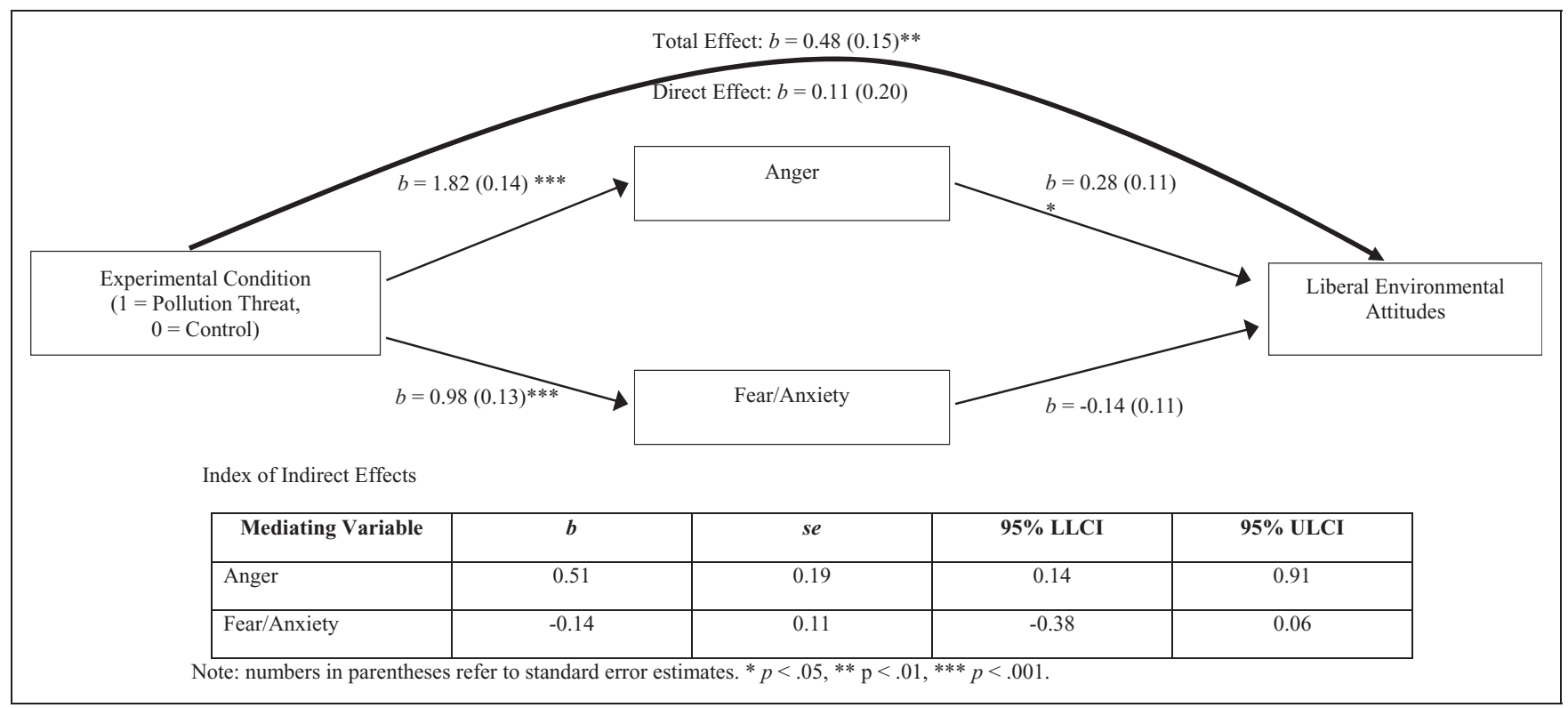

Figure 3. Mediation analyses on liberal environmental attitudes, Experiment 2, anger $(N=184)$. Index of indirect effects.

the other political attitudes (social liberalism, social conservatism, hawkish attitudes, and health-care attitudes) similarly to Experiment 1 but used fewer items for each construct (See Online Supplement [Appendix C]).

\section{Results}

\section{Effects of Priming Condition on Mood}

Compared to participants in the control condition, we expected and found higher levels of anger among participants assigned to the threat condition $M=2.99$ (95\% CI [2.79, 3.19]) versus 1.17 $(95 \%$ CI $[0.97,1.37]), F(1,182)=163.41, p<.001, \eta^{2}=0.47$, and this was also true with respect to fear/anxiety $M=2.33$ (95\% CI $[2.14,2.52])$ versus $M=1.35$ (95\% CI [1.16, $1.53]), F(1,182)=54.61, p<.001, \eta^{2}=0.23$.

\section{Effects of Priming Condition on Political Attitudes}

As predicted, participants assigned to the pollution threat condition (vs. control) expressed greater support for liberal environmental attitudes, $M=5.65$ (95\% CI [5.44, 5.85]) versus $M=5.16$ (95\% CI $[4.96,5.37]), F(1,182)=10.72, p=$ $.001, \eta^{2}=0.06$.

\section{Mediation Analyses}

We performed mediation analyses using Model 4 of Hayes's PROCESS Macro (2018), with priming condition serving as the independent variable $(X)$, anger $(M 1)$ and fear/anxiety (M2) serving as mediators, and environmental attitudes serving as the outcome measure (Y). As shown in Figure 3, analyses provided strong evidence of affective mediation, as higher levels of anger, but not fear/anxiety, correlated with liberal environmental attitudes.

\section{Supplemental Analyses With Other Attitude Indices}

We also examined whether there were between-subject differences on social conservatism, general social liberalism, liberal health-care attitudes, and hawkish military indices. Of these indices, we found differences (threat vs. control) on liberal health-care attitudes, $M \mathrm{~s}=4.91$ (1.18) versus 4.48 (1.32), $F(1,182)=5.56, p=.02, \eta^{2}=0.03$, and social conservatism, $M \mathrm{~s}=2.98(1.29)$ versus $3.39(1.26), F(1,182)=4.93, p=.03$, $\eta^{2}=0.03$, indicating participants in the threat condition were more supportive of liberal health-care attitudes and were less likely to support social conservatism. In contrast, there were no differences for our general measure of social liberalism, $M \mathrm{~s}=4.90(1.22)$ versus $4.62(1.31), F(1,182)=2.26, p=$ $.14, \eta^{2}=0.01$, nor were there differences on hawkish attitudes, $M \mathrm{~s}=4.18(1.58)$ versus $4.46(1.61), F(1,182)=1.42, p=.24$, $\eta^{2}=0.01$.

\section{Experiment 3}

Experiments 1 and 2 provide consistent evidence that if the activated threat is in domains in which liberals "own," participants would be more supportive of those aspects of liberalism. Nevertheless, one drawback from these studies is that both threats involved children, raising an important alternative hypothesis: threats involving children increased support for liberal attitudes. To offset this possibility, our third experiment did not include a threatening context involving children. Moreover, Experiment 3 examined a different domain in which liberals carry perceptual "ownership": corporate misconduct. Indeed, Democrats (vs. Republicans) generally claim ownership in controlling the power of large corporations and dealing with corporate financial fraud (ABC-Washington Post, 2002). 


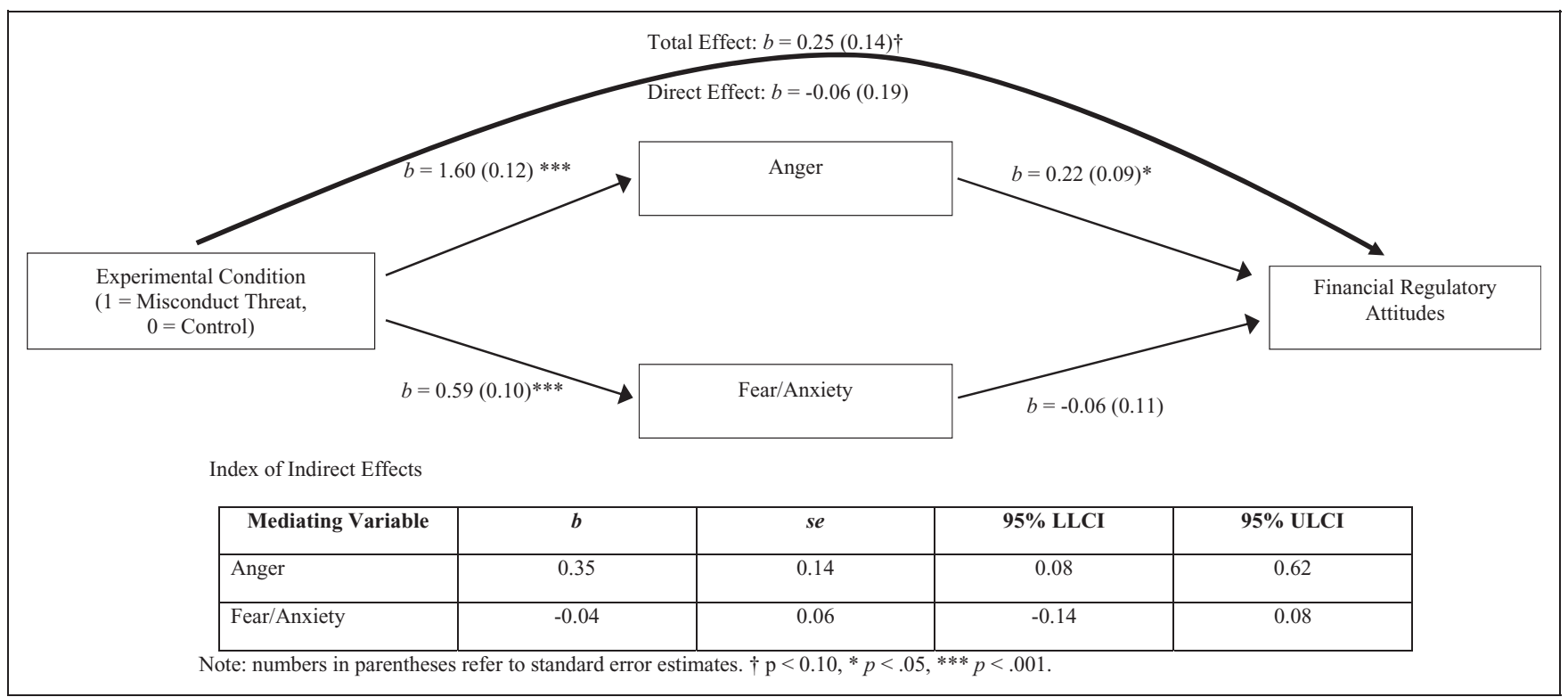

Figure 4. Mediation analyses on financial regulatory attitudes, Experiment 3, anger $(N=225)$. Index of indirect effects.

Participants in this experiment read about corporate conduct from the 2008 financial crisis (vs. control). We predicted participants in this threat (vs. control) would increase the support for financial regulation.

\section{Method}

\section{Participants and Design}

A total of 225 participants ( 82 male, 141 female, 1 other, 1 did not answer) from the United States were recruited from MTurk. The design included a between-subjects manipulation of priming threat (financial threat vs. control). After completing a standard mood inventory, all participants evaluated a series of political statements.

\section{Financial Crisis Prime}

Participants in this condition read a summary of the 2008 financial crisis, which detailed predatory lending tactics taken by many large banks, the bundling of mortgage-backed securities, and chronicles a wrongly foreclosed homeowner. After reading this article, participants completed the same writing task from previous experiments, with similar length constraints.

\section{Control Prime}

The control prime (food allergies) was identical to previous experiments and was accompanied by the same length constraints as the financial threat condition.

\section{Mood and Political Attitudes}

Anger $(\alpha=.96)$ and fear/anxiety $(\alpha=.93)$ were collected in a similar fashion to earlier experiments. Since the threat activated in Experiment 3 involved corporate misconduct by the banking industry, we examined financial regulatory attitudes. These 14 items revolved around the regulation of financial institutions and increasing consumer financial protections. A composite based on the average of these items was formed $(\alpha=.93)$. We also measured all other political attitudes indices seen in our previous studies. However, none of these indices, presented in Online Supplement (Appendix D), approached statistical significance, all $F_{\mathrm{s}}<1.00$, all $p \mathrm{~s}>.25$.

\section{Results}

\section{Effects of Priming Condition on Mood}

We expected and found participants expressed greater levels of anger if they were assigned to the financial threat versus control condition, $M=2.76$ (95\% CI $[2.59,2.93])$ versus $1.16(95 \%$ CI $[0.99,1.33]), F(1,223)=229.64, p<.001$, $\eta^{2}=0.51$. Parallel effects were found for fear/anxiety, $M=$ 1.96 (95\% CI $[1.83,2.10])$ versus $M=1.37$ (95\% CI [1.23, $1.51]), F(1,223)=35.36, p<.001, \eta^{2}=0.14$.

\section{Effects of Priming Condition on Attitudes}

We expected and found that assignment to the financial threat (vs. control) condition marginally increased the support for liberal regulatory solutions, $M s=5.06(95 \%$ CI $[4.86,5.26])$ versus. $4.81(95 \%$ CI $[4.61,5.01]), F(1,223)=3.02, p=.08, \eta^{2}=0.01$.

\section{Mediation Analyses}

Mediation analyses were employed, using Model 4 of Hayes's (2018) PROCESS macro. Experimental condition served as the independent variable $(X)$, anger and fear/anxiety $(M 1-M 2)$ served as mediators, and regulatory attitudes served as the outcome measure (Y). These findings, presented in Figure 4, provide evidence for anger-fueled mediation. 


\section{General Discussion}

The current research demonstrates the link between threat and political attitude change is context-specific and shows that threat is capable of pushing people to the political left. Although previous research finds threat increases support for political conservatism, the nature of these threats are almost always in contexts that conservatives own. What has been untested are threats in which liberals claim perceptual ownership (i.e., health care, environment).

Taken in isolation, our findings could be criticized on the grounds that the threats shown to elicit proliberal shifts are different from other types of threats known to reliably elicit pro-conservative responses (especially, terrorist threats). The preliminary study, presented earlier, strongly contradicts this idea. Indeed, the "left-triggering" primes were equivalent to terrorist threat with respect to (a) affective reactions and (b) perceived personal and collective threat. In other words, these data strongly suggest our primes were just as threatening as terrorist threat. The key difference is that our threats were relevant to a problem for which liberals - not conservatives - are stereotypically perceived to be more effective at solving. We hypothesized threats in these domains would increase the support for liberalism.

Participants in Experiment 1 read about a health-care threat. Experiment 2 examined pollution threats. Finally, Experiment 3 examined a corporate misconduct threat (vs. control). In all cases, threat increased the support for the relevant component of liberalism, with anger, but not fear/ anxiety, serving a causal role. These findings fill a gap in the literature, broadening threat as a psychological construct and its effects on political attitudes.

Of course, additional work is needed to delineate when threat produces support for political conservatism and when it produces the support for political liberalism. How might one develop such a taxonomy? We believe the issue ownership literature provides a starting point. Indeed, an overview by Seeberg (2017) charts issue ownership in 17 countries over three decades and finds conservatives claim ownership over asylum, "law and order," and taxation, whereas liberals own the environment, health care, and social welfare policies. Our findings clearly fit this pattern. Thus, it is likely that changes in political attitudes after a threat elevates support for political groups or issues that have perceptual ownership over this threat.

In sum, the link between threat and political ideology has important theoretical and practical ramifications. This is important in our work, as we believe providing a better understanding for when threat "shifts" people to the left, or to the right, can affect support for political actors and voting behavior. In short, we hope this research generates future scholarly investigation and carries far-reaching consequences as it relates to public policy.

\section{Acknowledgments}

This research was conducted as part of the first author's doctoral dissertation under the supervision of Alan Lambert. The author would also like to thank committee members Michael Strube, Joshua Jackson, Heike Winterheld, and Hillary Anger Elfenbein. Experiment 2 was conducted as part of the second author's senior honors thesis under the direction of Dr. Alan Lambert

\section{Declaration of Conflicting Interests}

The author(s) declared no potential conflicts of interest with respect to the research, authorship, and/or publication of this article.

\section{Funding}

The author(s) received no financial support for the research, authorship, and/or publication of this article.

\section{Notes}

1. Although the choice of these items was somewhat arbitrary, we also examined our findings using distinct measures of anger (angry, mad, irate, furious; all $\alpha \mathrm{s}>.96$ ) and disgust (disgusted, revulsion, repulsed, nauseated, sickened; all $\alpha$ s $>0.94)$. Analyses indicated a nearly identical pattern of results across all three experiments.

2. One wave from Experiment 1 included a terrorist threat priming condition. This manipulation, compared to our control, produced "shifts to the right" (Jost et al., 2003[AQ7]; 2017; Lambert et al., 2010), which were interesting but less relevant to the current article.

3. At the end of each study, we also collected self-reported political orientation, using a 7 -point scale $(1=$ extremely liberal, $7=$ extremely conservative) in order to examine whether there was any evidence of moderated mediation. These analyses are reported in our Online Supplement (Appendix F). In general, however, there was no evidence that the link between threat and the focal attitude index (X-Y) was contingent on participants' preexisting political leanings.

4. One wave of this experiment contained eight additional political statements. The results using the expanded indices were virtually identical to using the original set of items in Experiment 1. For simplicity, the main text only presented analyses on items that were featured in all waves of Experiment 1.

\section{Supplemental Material}

The supplemental material is available in the online version of the article.

\section{References}

Carver, C. S., \& Harmon-Jones, E. (2009). Anger is an approachrelated affect: Evidence and implications. Psychological Bulletin, 135, 183-204.

Cottrell, C. A., \& Neuberg, S. L. (2005). Different emotional reactions to different groups: A sociofunctional threat-based approach to "prejudice." Journal of Personality and Social Psychology, 88, 770-789. doi:10.1037/0022-3514.88.5.770

Eadeh, R. F. (2007). Healthcare vs. Hawkishness: The divergent effects of affect on context-driven shifts in attitudes. (Doctoral dissertation). Retrieved from https://openscholarship.wustl.edu/art_ sci_etds/1098/[AQ8] 
Egan, P. (2013). Partisan Priorities: How issue ownership drives and distorts American Politics. New York, NY: Cambridge University Press.

Gibson, J. (1977). "The theory of affordances." In R. Shaw \& J. Bransford (Eds.), Perceiving, acting, and knowing. Hillsdale, NJ: Lawrence Erlbaum.

Hayes, A. F. (2018). Partial, conditional, and moderated moderated mediation: Quantification, inference, and interpretation. Communication Monographs, 85, 4-40.

Huddy, L., Feldman, S., \& Cassese, E. (2007). On the distinct political effects of anxiety and anger. The affect effect: Dynamics of emotion in political thinking and behavior, 202-230.[AQ9]

Hutcherson, C. A., \& Gross, J. J. (2011). The moral emotions: A social-functionalist account of anger, disgust, and contempt. Journal of Personality and Social Psychology, 100, 719-737.

Jost, J., Stern, C., Rule, N., \& Sterling, J. (2017). The politics of fear: Is there an ideological asymmetry in existential motivation? Social Cognition, 35, 324-353.

Lambert, A. J., Eadeh, F. R., Peak, S. A., Scherer, L. D., Schott, J. P., \& Slochower, J. M. (2014). Toward a greater understanding of the emotional dynamics of the mortality salience manipulation: Revisiting the "affect-free" claim of terror management research. Journal of Personality and Social Psychology, 106, 655-678.

Lambert, A. J., Eadeh, F. R., \& Hanson, E. J. (in press). Anger and its consequences for judgment and behavior: Recent developments in social and political psychology. Advances in Experimental Social Psychology.[AQ10]

Lambert, A. J., Scherer, L. D., Schott, J. P., Olson, K. R., Andrews, R. K., O'Brien, T. C., \& Zisser, A. R. (2010). Rally effects, threat, and attitude change: An integrative approach to understanding the role of emotion. Journal of Personality and Social Psychology, 98, 886-903.

Litvak, P., Lerner, J. S., Tiedens, L. Z., \& Shonk, K. (2010). Fuel in the fire: How anger impacts judgment and decision making. In M. Potegal, G. Stemmler, \& C. Spielberger (Eds.), International Handbook of Anger (pp. 287-311). New York, NY: Springer.

Nabi, R. L. (2002). The theoretical versus the lay meaning of disgust: Implications for emotion research. Cognition and Emotion, 16, 695-703.

Newport, F. (2014, September11). Republicans expand edge as better party against terrorism. Gallup website. Retrieved from news. gallup.com/poll/175727/republicans-expand-edge-better-partyagainst-terrorism.aspx

Petrocik, J. R. (1996). Issue ownership in presidential elections, with a 1980 case study. American Journal of Political Science, 40, $825-850$

Saad, L. (2007). Democratic party winning on issues, December 7. Retrieved from http://news.gallup.com/poll/103102/democraticparty-winning-issues.aspx

Seeberg, H. (2017). How stable is political parties' issue ownership? A cross-time, cross-national analysis. Political Studies, 65, 475-492.

Threat. Def 2. (2018). In Oxford English dictionary. Retrieved from https://en.oxforddictionaries.com/definition/threat

Washington Post-ABC. (2002, December 18). Washington Post$\mathrm{ABC}$ news poll. Washington Post website. Retrieved from http://www.washingtonpost.com/wp-srv/politics/polls/vault/stor ies/data121802.html

\section{Author Biographies}

\section{[AQ1]}

